\title{
Telemedicine for adults with cochlear implants in the UK (CHOICE): protocol for a prospective interventional multi-site study
}

Helen Cullington, Padraig Kitterick, Philippa Darnton, Tracy Finch, Kate Greenwell, Carol Riggs, Mark Weal, Dawn-Marie Walker, Andrew Sibley

Submitted to: JMIR Research Protocols

on: January 18, 2021

Disclaimer: () The authors. All rights reserved. This is a privileged document currently under peer-review/community review. Authors have provided JMIR Publications with an exclusive license to publish this preprint on it's website for review purposes only. While the final peer-reviewed paper may be licensed under a CC BY license on publication, at this stage authors and publisher expressively prohibit redistribution of this draft paper other than for review purposes. 


\section{Table of Contents}

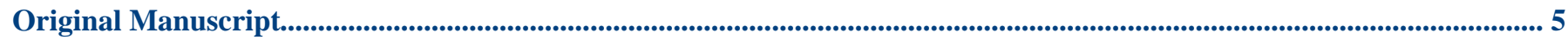

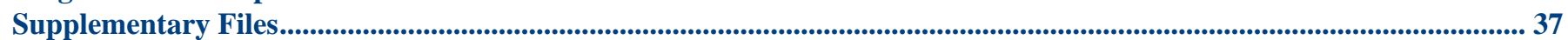

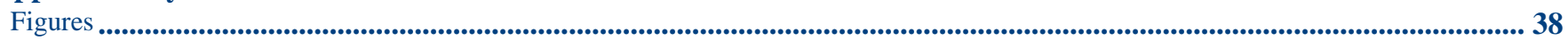

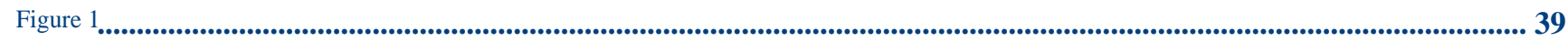

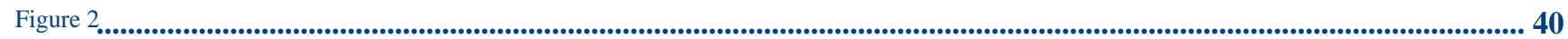

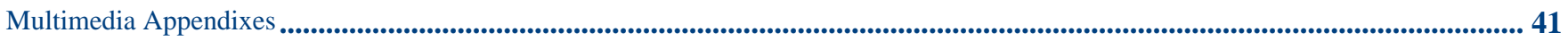

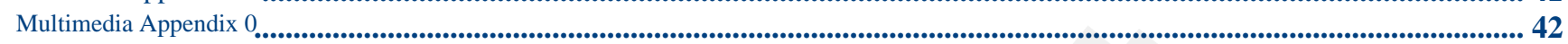




\section{Telemedicine for adults with cochlear implants in the UK (CHOICE): protocol for a prospective interventional multi-site study}

Helen Cullington ${ }^{1}$ BSc, MA, MSc, PhD; Padraig Kitterick ${ }^{2}$ BMusPerf, MSc, PhD; Philippa Darnton ${ }^{3}$ MSc; Tracy Finch $^{4} \mathrm{PhD}$; Kate Greenwell ${ }^{5} \mathrm{BSc}, \mathrm{MSc}, \mathrm{CPsychol}$, PhD; Carol Riggs ${ }^{1}$; Mark Weal ${ }^{6}$ BSc, PhD; Dawn-Marie Walker ${ }^{7}$ BSc, MSc, MA, PhD; Andrew Sibley ${ }^{3}$ BSc, MSc, PhD

\footnotetext{
${ }^{1}$ University of Southampton Southampton GB

${ }^{3}$ Wessex Academic Health Science Network Southampton GB

${ }^{4}$ Northumbria University Newcastle upon Tyne GB

${ }^{7}$ School of Health Sciences University of Southampton Southampton GB

\section{Corresponding Author:}

Helen Cullington BSc, MA, MSc, PhD

University of Southampton

University of Southampton Auditory Implant Service

Southampton

GB
}

${ }^{2}$ National Institute for Health Research Nottingham Hearing Biomedical Research Unit Nottingham GB

${ }^{5}$ Centre for Clinical and Community Applications of Health Psychology University of Southampton Southampton GB

${ }^{6}$ University of Southampton School of Electronics and Computer Science Southampton GB

\section{Abstract}

\section{Introduction}

Cochlear implants provide hearing to more than 600,000 people with deafness worldwide; patients require lifelong follow-up. Care for adults with implants in the UK occurs at one of 19 centres, which may be far from the patient's home. In a previous RCT, we successfully introduced person-centred care. We designed, implemented and evaluated a remote care pathway: a personalised online support tool, home hearing check, self device adjustment, and upgrading of sound processors at home rather than in clinic.

The remote care group had a significant increase in empowerment after using the tools; patients and clinicians were keen to continue. We would now like to scale up these improvements as an option to the more than 12,000 UK adults using implants; we are commissioning an independent evaluation of this intervention and roll out to establish if it achieves its aims of more empowered and confident patients; more accessible and equitable care; stable hearing; more efficient, person-centred and scalable service; more satisfied and engaged patients and clinicians.

Methods and analysis

This project will scale up and evaluate a person-centred long-term follow-up pathway for adults using cochlear implants using a personalised website including a home hearing check, upload of photos of cochlear implant site, listening in noise and music practice, spares ordering, questionnaires, and other resources. Both quantitative and qualitative analyses will occur.

Ethics and dissemination

Ethical approval was received in November 2018 from the South Central - Hampshire A Research Ethics Committee (REC reference 18/SC/0658, IRAS project ID 242575) and HRA and Health and Care Research Wales (HCRW).

Results will be disseminated in the clinical and scientific communities and also to the patient population via peer-reviewed research publications both online and in print, conference and meeting presentations, posters, newsletter articles, website reports, and social media. 


\section{Preprint Settings}

1) Would you like to publish your submitted manuscript as preprint?

$\checkmark$ Please make my preprint PDF available to anyone at any time (recommended).

Please make my preprint PDF available only to logged-in users; I understand that my title and abstract will remain visible to all users. Only make the preprint title and abstract visible.

No, I do not wish to publish my submitted manuscript as a preprint.

2) If accepted for publication in a JMIR journal, would you like the PDF to be visible to the public?

$\checkmark$ Yes, please make my accepted manuscript PDF available to anyone at any time (Recommended).

Yes, but please make my accepted manuscript PDF available only to logged-in users; I understand that the title and abstract will remain Yes, but only make the title and abstract visible (see Important note, above). I understand that if I later pay to participate in <a href="http 


\section{Original Manuscript}




\section{Telemedicine for adults with cochlear implants in the UK (CHOICE): protocol for a prospective interventional multi-site study}

Short title: CHOICE - cochlear implant home care

Cullington, Helen; Kitterick, Padraig; Darnton, Philippa; Finch, Tracy; Greenwell, Kate; Riggs, Carol; Weal, Mark; Walker, Dawn-Marie; Sibley, Andrew.

\section{Helen Cullington}

University of Southampton Auditory Implant Service

Highfield

Southampton

SO17 1BJ

United Kingdom

H.Cullington@Southampton.ac.uk

Padraig Kitterick

Head of Hearing Sciences

National Institute for Health Research Nottingham Hearing Biomedical Research Unit

Ropewalk House

Nottingham

NG1 5DU

United Kingdom

01158232626

Padraig.Kitterick@Nottingham.ac.uk

Philippa Darnton

Associate Director Insight

Wessex Academic Health Science Network

Innovation Centre

Southampton Science Park

2 Venture Road

Chilworth 
SO16 7NP

\section{Philippa.Darnton@Wessexahsn.net}

Tracy Finch

Professor of Healthcare \& Implementation Science

Department: Nursing, Midwifery \& Health

Campus West

Northumbria University

Newcastle upon Tyne

NE7 7XA

United Kingdom

01912156477

Tracy.Finch@Northumbria.ac.uk

Kate Greenwell

Senior Research Fellow

Centre for Clinical and Community Applications of Health Psychology, School of Psychology, Faculty of Environmental and Life Sciences

University of Southampton

Highfield

Southampton

SO17 1BJ

United Kingdom

02380595077

\section{K.Greenwell@soton.ac.uk}

\section{Carol Riggs}

Patient/service user at

University of Southampton Auditory Implant Service

Highfield

Southampton

SO17 1BJ

United Kingdom

Mark Weal

University of Southampton School of Electronics and Computer Science 
Highfield

Southampton

SO17 1BJ

United Kingdom

02380599400

mjw@ecs.soton.ac.uk

Dawn-Marie Walker

Associate Professor

School of Health Sciences

University of Southampton

Highfield

Southampton

SO17 1BJ

United Kingdom

02380595289

dawn-marie.walker@soton.ac.uk

Andrew Sibley

Programme Manager - Evaluation

Wessex AHSN

Innovation Centre

Southampton Science Park

2 Venture Road

Chilworth

SO16 7NP

andrew.sibley@wessexahsn.net

Corresponding author:

Helen Cullington

University of Southampton Auditory Implant Service

Highfield

Southampton

SO17 1BJ 
United Kingdom

Email ‥Cullington@Southampton.ac.uk

Telephone + 442380597606

\section{Author contributions}

Clinical conception and design: HC, PK

Evaluation conception and design: PD, AS

Drafting of protocol: all

Critical revision of the manuscript: all

Obtaining funding: all

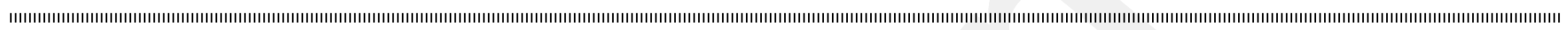

\section{Research reference numbers}

This paper is abbreviated from protocol version 1.711 June 2020.

\begin{tabular}{|l|l|}
\hline IRAS & 242575 \\
\hline ISRCTN & ISRCTN51668922 \\
\hline Sponsor's number & ERGO 40383 \\
\hline
\end{tabular}




\section{Abstract}

\section{Background}

Cochlear implants provide hearing to around 750,000 people with deafness worldwide; patients require lifelong follow-up. Care for adults with implants in the UK occurs at one of 19 centres, which may be far from the patient's home. In a previous RCT, we successfully introduced person-centred care. We designed, implemented and evaluated a remote care pathway: a personalised online support tool, home hearing check, self device adjustment, and upgrading of sound processors at home rather than in clinic.

The remote care group had a significant increase in empowerment after using the tools; patients and clinicians were keen to continue. We would now like to scale up these improvements as an option to the more than 12,000 UK adults using implants; we are commissioning an independent evaluation of this intervention and roll out to establish if it achieves its aims of more empowered and confident patients; more accessible and equitable care; stable hearing; more efficient, person-centred and scalable service; more satisfied and engaged patients and clinicians.

\section{Objectives}

To evaluate the impact and roll out of a person-centred clinical care pathway via telemedicine for adults with cochlear implants in the UK, using both outcomes and process evaluation.

\section{Methods}

This project will scale up and evaluate a person-centred long-term follow-up pathway for adults using cochlear implants using a personalised website including a home hearing check, upload of photos of cochlear implant site, listening in noise and music practice, spares ordering, questionnaires, and other resources. Both quantitative and qualitative analyses will occur, and it will be both an outcomes and process evaluation.

\section{Results}

As of July 2021, the trial is closed, and all data collection is complete. The evaluation report is expected to be published in December 2021; the research data have not been analysed yet.

\section{Conclusions}


This project will present results of the first scaling up of a remote care pathway for adults with cochlear implants in the UK.

Trial registration

International Standard Randomized Controlled Trial Number (ISRCTN) 51668922;

https://www.isrctn.com/ISRCTN51668922

Key words

Cochlear Implants; Hearing; Deafness; Telemedicine; Patient-Centered Care 


\section{introduction}

Cochlear implants are the most successful of all neural prostheses;[1] they can provide hearing to people with severe to profound deafness. Approximately 1,600 people receive a cochlear implant in the United Kingdom (UK) each year.[2] The total number of people with implants is approximately 20,000 in the UK[estimated from 2] and around 0.75 million worldwide (estimated from [3], [4] and [5]). Numbers are likely to increase rapidly: only approximately $5 \%$ of eligible people in the UK and globally have received an implant, $[4,6]$ and the number of people of retirement age is projected to increase by $28 \%$ by 2035 [7] meaning a further increase in the number of people with hearing impairment. Adult cochlear implant care in the UK is provided at one of 19 tertiary centres involving assessment, surgery, and a resource-intensive acute phase of device adjustment and rehabilitation. When a patient attends a long-term follow-up appointment, the following tasks may be done: speech recognition testing, device adjustment, rehabilitation, equipment check and troubleshooting, and provision of replacement or upgraded equipment. Currently UK implant centres review patients on a clinicled schedule; this means that review appointments that provide little benefit to the patient can occur. Conversely, when some patients attend a routine appointment, there is hearing deterioration which the patient had not noticed. This is often remedied by replacing equipment that the patient could have done at home.

Cochlear implant centres may be several hours away from the patient's home necessitating travel expense, time off work and family disruption; distance to care is a significant barrier for hearing care globally. [8] Making this care pathway person-centred instead may provide a more efficient and effective service and allow more timely identification of issues; evidence suggests that person-centred care can improve a range of factors, including patient experience, care quality and health outcomes, and may help clinics manage the growing number of people with long-term conditions[9].

We previously designed and implemented a remote care pathway for adults with cochlear implants to enable them to do some of the follow-up tasks themselves at home. We ran a 6 month clinical trial with 60 people randomised to either a telemedicine remote care pathway or a control group who followed their usual appointment schedule.[10] The main outcome evaluated was patient empowerment; this has been shown to be strongly linked to better outcomes in people with long-term conditions. We found that only the remote care group had a significant increase in their cochlear implant empowerment after using the remote care tools.[11] Quality of life remained unchanged in the two groups. The hearing check result in clinic had improved in the remote care group, although they had not noticed a change. The control group, however, felt their hearing had become slightly worse. This may suggest that the remote care group were more able to take action to keep their hearing stable during the trial, or perhaps that the control group felt they were missing out on a desirable 
opportunity to take a more active role in their hearing healthcare.

Discontinuing routine appointments and attending the clinic only when there is clinical need may provide the following benefits for patients using cochlear implants:

- $\quad$ more stable hearing (problems identified and resolved quicker)

- $\quad$ better hearing (ability to fine tune when away from clinic)

- $\quad$ convenience of not travelling to routine appointments

- $\quad$ reduction of travel cost and time, time off work and disruption to family life

- $\quad$ increased confidence to manage own hearing

- $\quad$ greater equality in service delivery (same level of service regardless of distance from clinic)

It may also mean that the clinic has greater resources (time, money, space) to see patients with more complex needs and the expanding population of new patients. People using cochlear implants and their families would generally like to take a more active role in their care and welcome the use of technology to assist self-care. $[12,13]$ The NHS has a strong commitment to promoting self-care and self-management [14] for people with long-term conditions [15] with 'the vision of a citizen-centred, digitally-enabled, health and social care system'.[16] Evidence shows a significant improvement in outcomes when patients use self-management tools [17] and those who are activated and involved in their care tend to have better health outcomes.[18, 19]

We are now ready to scale up the successful remote care intervention to many more people with cochlear implants in the UK.

\section{Objectives}

To evaluate the impact and roll out of a person-centred clinical care pathway via telemedicine for adults with cochlear implants in the UK, using both outcomes and process evaluation.

\section{Methods}

\section{Project design and setting}

This is a prospective interventional multi-site Quality Improvement project, led and sponsored by the University of Southampton. All research measures will be self-administered online or by paper questionnaire, at the patient's home or other location of their choice. Staff will complete the measures at work or at a 
location of their choosing. Data collection will begin when the first site opens (11 June 2019) and will run until 31 January 2021. Clinics will join the study when appropriate local approvals are obtained, so it is likely that follow-up at each clinic will be for different durations.

\section{Intervention}

This project introduces a remote care pathway option to adults using cochlear implants: cochlear implant home care (CHOICE). We have built a personalised scalable responsive webapp (accessible from any internet browser, not a native application) based on our previously-trialled CIRCA (Cochlear Implant Remote Care) website (built in LifeGuide [20]). It incorporates a home hearing check based on the Triple Digit Test,[21] personalised reminders (e.g. change microphone cover), rehabilitation exercises (listening in noise, music and telephone practice), uploading a photo of cochlear implant surgery site (behind the ear) for review by their clinical care team, information and training, logging how many hours they use their cochlear implant (optional, self-reported only), evaluation measures, ordering replacement parts for their cochlear implant, emotional support resources, and questionnaires (Figure 1). The home hearing check provides a screen for whether the patient should come to clinic or not, based on comparison with a baseline check. Speech perception in noise testing using spoken digits (e.g. 'one') has the advantage of digits being highly familiar stimuli usually known by people with even limited language skills. Digit testing requires a closed set response and thus is suitable for self-testing over the telephone or internet [22, 23] and has a minimal learning effect.[24] The test correlates well with speech recognition in noise with sentences in people using cochlear implants.[25-28]

It is vital that patients remain vigilant to prevent medical issues related to their cochlear implant. This mainly involves appropriate action with ear infections (following the centre's protocol) and checking the site of the implant and skin under the coil magnet. The CHOICE website advises the patient to contact their clinical care centre with any medical concerns. The webapp has the functionality to upload and store photos of the patient's implant site. Patients are asked to take a baseline photo at an early stage to provide comparison for later images. 


\section{Figure 1. CHOICE webapp patient dashboard.}

Welcome back
Last logged in: 18/02/2020

Home My profile Results
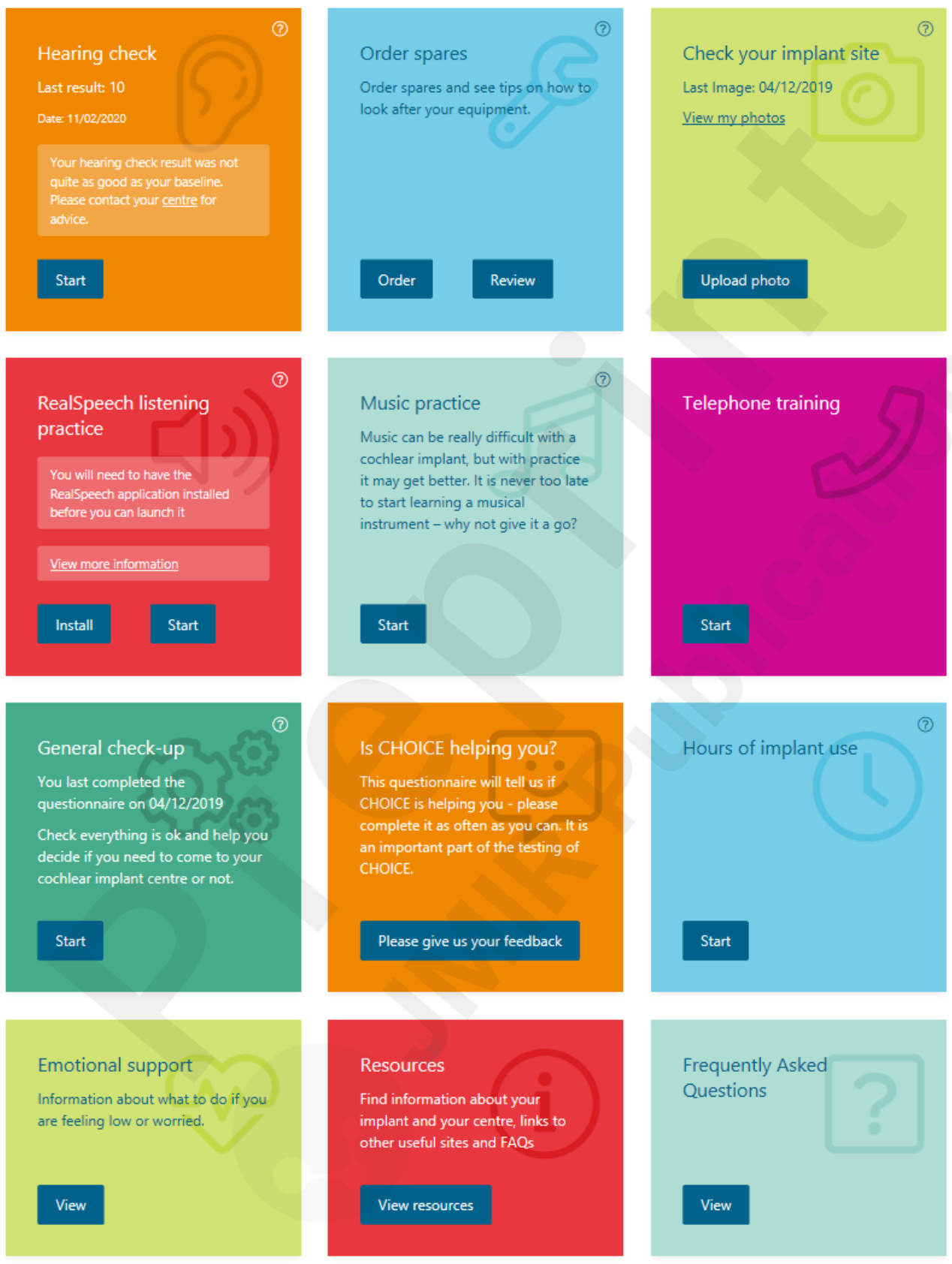

The patient's clinician at their cochlear implant centre will have access to their results and webapp usage in the CHOICE online clinician dashboard. Cochlear implant centre clinic appointments will be given if 
required, requested, or indicated by the outputs of the remote care tools. Otherwise the patients on this pathway will continue with remote care. Participants may access the webapp tools as often as they wish.

Automated flagging by email and website notifications will be the cornerstone of the remote care pathway. This will ensure that patient problems are not missed and will provide the most efficient use of clinician time. Some patient flagging situations are:

- $\quad$ no interaction with CHOICE for 3 months

- $\quad$ hearing deterioration

- $\quad$ patients who indicate that they need help on the general check-up questionnaire

- $\quad$ each time a photo is uploaded, clinicians will need to review it

- $\quad$ replacement stock items are required

- $\quad$ patient reports their daily sound processor use is less than 6 hours

- $\quad$ request to leave CHOICE

- $\quad$ Freedom of Information request

When an alert is received, the patient's clinician will decide whether further action is required, for example an in-centre appointment.

The CHOICE website conforms to the following specifications:

$$
\begin{array}{ll}
\text { Risk management } & \text { ISO 14971:2007 } \\
\text { Software lifecycle } & \text { BS EN 62304:2006 }
\end{array}
$$

and complies with the requirements of the EU directive:

$$
\text { 93/42/ECC for medical devices }
$$

It is CE marked and is registered with the MHRA as a Class I medical device.

\section{Participants}

Seven UK centres will offer CHOICE to their patients:

1. St Thomas' Hospital Hearing Implant Centre, London

2. University of Southampton Auditory Implant Service

3. Royal National Throat Nose and Ear Hospital, London

4. Nottingham Auditory Implant Programme 
5. North East Regional Cochlear Implant Programme, Middlesbrough

6. The Richard Ramsden Centre for Hearing Implants, Manchester

7. Emmeline Centre, Cambridge

All adult sites were contacted about CHOICE and its evaluation; these sites wanted to be involved. CHOICE is currently an intervention for adults only. Scaling up to only seven of the adult sites initially allows a detailed evaluation. Depending on the evaluation results, CHOICE may be offered to all sites in future.

\section{Proposed sample size}

We do not yet know what proportion of patients will choose to follow this pathway, as the previous work was a single-centre Randomised Controlled Trial that involved a limited number of patients.[10] However the seven centres care for around one third of the approximately 12,000 adults [29] with cochlear implants in the UK. At the early stages of project planning we estimated that if $40 \%$ of patients enrol, this may involve around 1700 patients. We expect this to be the upper limit of recruitment. Scaling up a digital health tool to people with cochlear implants has not been done before, so we cannot predict take up. We anticipate up to ten members of staff per site are involved (70). As the aim of the project is not to formally test a hypothesis, a sample size calculation has not been conducted.

\section{Recruitment}

We recommend shared decision making between the patient, their family and their clinician in order to decide who should be on a remote care pathway,[30] Factors that need to be considered include the patient's care needs, routine maintenance of equipment, access to technology, mobility, literacy, dexterity, any comorbidities e.g. visual impairment and other factors such as do they live alone, do they have transport etc. All patients who meet the inclusion criteria and, after discussing with their clinician as needed, choose the remote care pathway, will be invited to participate in the study. Only those who consent to the study will be able to continue with remote care at this stage. As patients' circumstances and abilities change, we recommend service delivery flexibility, with easy transfer to a clinic-based care model if required. Staff at participating centres will be invited to take part, and will sign a consent form for their data to be included in the evaluation. Recruitment commenced on June 112019 and continues until 31 January 2021.

\section{Patient inclusion criteria}

- Person using cochlear implant (any device, unilateral or bilateral)

- $\quad$ Living in the UK

- $\quad$ Aged 18 years or more

- Able to give informed consent to data sharing

- Access to a computer or device with internet access 
- Willing and able to comply with a cochlear implant home care pathway

- Willing and able to comply with the evaluation

\section{Health professional inclusion criteria}

- Staff at participating cochlear implant centres

\section{Evaluation and research outcomes}

Wessex Academic Health Science Network (AHSN) will perform an independent evaluation to assess the impact and success of the care pathway on patients, staff and services and to understand the process of implementing CHOICE, using a concurrent triangulation mixed methods design. It will be both an outcomes and process evaluation. The evaluation was commissioned in September 2017, and is informed by a growing research base on the challenges associated with the adoption and spread of digital programmes. The research team will collect clinical outcome measures. All outcomes, methods and measures corresponding to the research questions are shown in Table 1.

\section{Primary Research Questions}

1) Evaluation: What is the impact of the roll out of the new care pathway on users of the programme (people with cochlear implants and staff)?

2) Research: Does the new care pathway increase empowerment for people with cochlear implants while having no detrimental effect on their hearing and quality of life?

\section{Secondary Research Questions}

3) What is the extent of spread of the new care pathway?

a) What has facilitated adoption of the new care pathway?

b) What has hindered adoption of the new care pathway?

4) Does the new care model improve patients' confidence to self-manage their cochlear implant as measured by patient-reported outcomes of health confidence, health status and personal wellbeing?

a) Do patients initiate review appointments with the service rather than rely on or wait for appointments scheduled by the service?

5) Does the new care model improve patients' experience of follow-up care?

a) Do patients engage with the technology as measured by patient reported outcomes of digital confidence and perceived value of the tool?

6) Does the new care model improve equity of access to follow-up care?

7) Does the new model of care improve the experience of staff working in the service as measured by staff 
reported outcomes of job confidence and work wellbeing.

a) Do staff have confidence in the new care model as measured by staff reported outcomes of digital confidence and perceived value of the tool?

b) Do they recommend it?

8) Does the new care model improve use of resources through reducing the need for follow-up appointments and enabling the service to be delivered by a different skill mix?

9) What lessons can be learned from the implementation process that will benefit spread and adoption of this model?

Table 1. Outcomes, methods and measures collected from patients (blue), staff (green) and services (orange). Column 2 relates each outcome to a Research Question (RQ)

\begin{tabular}{|c|c|c|c|c|}
\hline Outcome & RQ & Method & Measures & Timepoint \\
\hline $\begin{array}{l}\text { Patient impact } \\
\text { (engagement) }\end{array}$ & 1 & Quantitative & $\begin{array}{l}\text { CHOICE webapp data: } \\
\text { number of logins, time spent } \\
\text { on CHOICE, uses of self } \\
\text { device adjustment (if } \\
\text { appropriate), uses of home } \\
\text { hearing check }\end{array}$ & All data \\
\hline $\begin{array}{l}\text { Patient impact } \\
\text { (quality) }\end{array}$ & 1 & Quantitative & $\begin{array}{l}\text { Number of errors in } \\
\text { CHOICE, adverse events, } \\
\text { missed issues }\end{array}$ & All data \\
\hline Patient impact & 1 & Quantitative & $\begin{array}{l}\text { Survey about use of follow- } \\
\text { up care (consequences for } \\
\text { travel cost, time, hours off } \\
\text { work, childcare (including } \\
\text { accompanying person)) }\end{array}$ & $\begin{array}{l}\text { Once at patient focus } \\
\text { group/interview }\end{array}$ \\
\hline Patient impact & 1 & Quantitative & NHS Friends and Family Test & $\begin{array}{l}\text { Minimum of twice. Baseline (on } \\
\text { registration) and after using } \\
\text { CHOICE for several months }\end{array}$ \\
\hline Patient impact & 1 & Qualitative & Focus groups & $\begin{array}{l}\text { Once. Planned, but unable to } \\
\text { happen due to Covid-19 }\end{array}$ \\
\hline Patient impact & 1 & Qualitative & One to one interviews & $\begin{array}{l}\text { Once. For patients who prefer } \\
\text { one-to-one interviews, or if focus } \\
\text { groups cannot occur. Towards } \\
\text { end of project }\end{array}$ \\
\hline $\begin{array}{l}\text { Patient } \\
\text { empowerment }\end{array}$ & 2 & Quantitative & $\begin{array}{l}\text { PAM questionnaire, CI-EMP } \\
\text { questionnaire }\end{array}$ & $\begin{array}{l}\text { Baseline (on registration) and } 6 \\
\text { months following registration or } \\
\text { end of project - whichever comes } \\
\text { sooner }\end{array}$ \\
\hline Patient hearing & 2 & Quantitative & Home hearing check results & All data \\
\hline $\begin{array}{l}\text { Patient change } \\
\text { in } \\
\text { empowerment, } \\
\text { hearing, } \\
\text { quality of life }\end{array}$ & 2 & Quantitative & $\begin{array}{l}\text { Global ratings of change } \\
\text { questionnaire }\end{array}$ & $\begin{array}{l}\text { Baseline (on registration) and } 6 \\
\text { months following registration or } \\
\text { end of project - whichever comes } \\
\text { sooner }\end{array}$ \\
\hline
\end{tabular}




\begin{tabular}{|c|c|c|c|c|}
\hline $\begin{array}{l}\text { Patient health- } \\
\text { related quality } \\
\text { of } \quad \text { life } \\
\text { including } \\
\text { hearing }\end{array}$ & 2 & Quantitative & HUI3 questionnaire & $\begin{array}{l}\text { Baseline (on registration) and } 6 \\
\text { months following registration or } \\
\text { end of project - whichever comes } \\
\text { sooner }\end{array}$ \\
\hline $\begin{array}{l}\text { Patient health- } \\
\text { related quality } \\
\text { of life }\end{array}$ & 2 & Quantitative & EQ-5D-5L questionnaire & $\begin{array}{l}\text { Baseline (on registration) and } 6 \\
\text { months following registration or } \\
\text { end of project - whichever comes } \\
\text { sooner }\end{array}$ \\
\hline $\begin{array}{l}\text { Patient } \\
\text { preference of } \\
\text { service } \\
\text { delivery } \\
\end{array}$ & 2 & Quantitative & $\begin{array}{l}\text { Discrete Choice Experiment } \\
\text { (DCE) questionnaire }\end{array}$ & $\begin{array}{l}\text { Baseline (on registration) and } 6 \\
\text { months following registration or } \\
\text { end of project - whichever comes } \\
\text { sooner }\end{array}$ \\
\hline $\begin{array}{l}\text { Patient } \\
\text { confidence and } \\
\text { experience }\end{array}$ & 4,5 & Quantitative & R-Outcomes surveys & $\begin{array}{l}\text { Baseline (on registration) and } \\
\text { every six months. Some } \\
\text { participants may choose to } \\
\text { complete an optional shorter } \\
\text { questions set more often }\end{array}$ \\
\hline $\begin{array}{l}\text { Staff impact } \\
\text { (engagement) }\end{array}$ & 1 & Quantitative & $\begin{array}{l}\text { CHOICE webapp data from } \\
\text { clinician dashboard: } \\
\text { number and type of logins }\end{array}$ & All data \\
\hline Staff impact & 1 & Quantitative & NHS Friends and Family Test & $\begin{array}{l}\text { Minimum of twice. Baseline (on } \\
\text { registration) and after using } \\
\text { CHOICE for several months }\end{array}$ \\
\hline Staff behaviour & 1 & Quantitative & NOMAD questionnaire & $\begin{array}{l}\text { At interview or by email, and by } \\
\text { email request towards the end of } \\
\text { the evaluation. }\end{array}$ \\
\hline Staff impact & 1,9 & Qualitative & Focus groups (staff) & $\begin{array}{l}\text { Once. Planned, but unable to } \\
\text { happen due to Covid-19 }\end{array}$ \\
\hline Staff impact & 1,9 & Qualitative & One to one interviews (staff) & $\begin{array}{l}\text { Once for key staff who are not } \\
\text { available for the on-site focus } \\
\text { group. Towards end of project }\end{array}$ \\
\hline $\begin{array}{l}\text { Staff } \\
\text { experience }\end{array}$ & 7 & Quantitative & R-Outcomes surveys & $\begin{array}{l}\text { Baseline (on registration) and } \\
\text { every } 6 \text { months }\end{array}$ \\
\hline $\begin{array}{l}\text { Spread, equity } \\
\text { of access, } \\
\text { resource use } \\
\text { (services) }\end{array}$ & $\begin{array}{l}3, \\
4,8\end{array}$ & Quantitative & Clinic activity information & See Appendix 1 for more details \\
\hline
\end{tabular}

\section{Patient outcomes}

\section{Quantitative measures}

All data will be downloaded from the CHOICE webapp and patients' usage of all elements of CHOICE including the hearing check will be assessed. Errors in CHOICE, adverse events and patient missed issues will be collected during the study period. Those patients that take part in the focus group/interview will be asked to complete a short survey about the cost implications of switching to remote care (e.g. impact on travel costs, need for childcare etc.). 
Quantitative data about patients' use of CHOICE will be collected using the R-Outcomes survey tool.[31] These measures share a common framework with 4 items and 4 responses suitable for use on a mobile device, and are validated, short and have a lower reading age than other measures. R-Outcomes are incorporated into CHOICE, and will assess patients' health, wellbeing, health confidence, digital readiness, and user experience. The NHS Friends and Family Test (FFT) is also incorporated into the CHOICE webapp; asking the question 'How likely are you to recommend this service to friends and family if they need similar care or treatment?' with six response options, ranging from "extremely likely" to "extremely unlikely”.[32]

We will use the following measures to assess empowerment, health-related quality of life, hearing and patient care pathway preference: the Patient Activation Measure ${ }^{\circledR}\left(\mathrm{PAM}{ }^{\circledR}\right)$, the Cochlear Implant Empowerment Scale (CI-EMP), the EuroQoL EQ-5D-5L, the Health Utilities Index Mark 3 (HUI3), a global change rating, and a Discrete Choice Experiment (DCE). The PAM ${ }^{\circledR}$ is a well-validated generic measure of patient activation that evaluates the knowledge, skills, beliefs and behaviours that patients have for self-management of their long-term condition.[33, 34] CI-EMP is a questionnaire specifically designed to measure how empowered people are to manage their own cochlear implant care.[35] The EQ-5D-5L is a standardised health outcome measure comprising five dimensions: mobility, self-care, usual activities, pain/discomfort and anxiety/depression.[36] The HUI Mark 3 (HUI3) is a multi-attribute health status classification system evaluating eight domains of vision, hearing, speech, ambulation, dexterity, emotion, cognition and pain.[37]

Global rating of change scales will be used to capture whether patients perceive a change in their hearing, empowerment and quality of life - to determine whether any changes observed on the PAM, CI-EMP, HUI3 or EQ-5D-5L are meaningful; i.e. whether they were perceived by patients.

We designed a discrete choice experiment to assess the effects of 5 care pathway attributes ('Who decides when the next clinic appointment will be?', 'When is the ability to understand speech monitored?', 'Who can fine-tune the cochlear implant?', 'Where can patients get rehabilitation and troubleshooting information that is personalised to their needs?', and 'How are upgrades to sound processors provided?') on the preferences of participants to remote care (Figure 2). Each attribute had three levels that described different approaches and degrees of remote care; e.g. the choices for who decides when the next clinic appointment will be "The implant clinic", "The patient", or "The implant clinic (but the patient can request appointments when required)". The experiment was constructed using the mix-and-match design method[38] as implemented in the 'support.CEs' package for the R statistical environment [39]. The experimental design was organised into two blocks to reduce the number of questions each individual participant had to complete; patients will be randomly assigned to complete either block 1 or block 2. The design requirements of 5 attributes per alternative, 2 alternatives per choice question, and 2 experimental blocks resulted in the allocation of 9 discrete choices per block. The role of the DCE is to help us learn about how the different elements of the 
care pathway interact to shape participant preferences for remote care compared to the usual pathway. It is possible that the preferences patients have for remote care could relate to their outcomes, and we will explore those relationships using exploratory correlational analyses.

\section{Figure 2. The five elements of the Discrete Choice Experiment.}

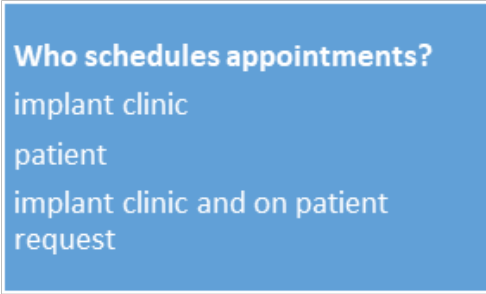

When is speech understanding monitored?

during appts only by audiologist

only by patient at home

both
Who can fine tune the implant?

during appts only by audiologist

only by patient at home

both
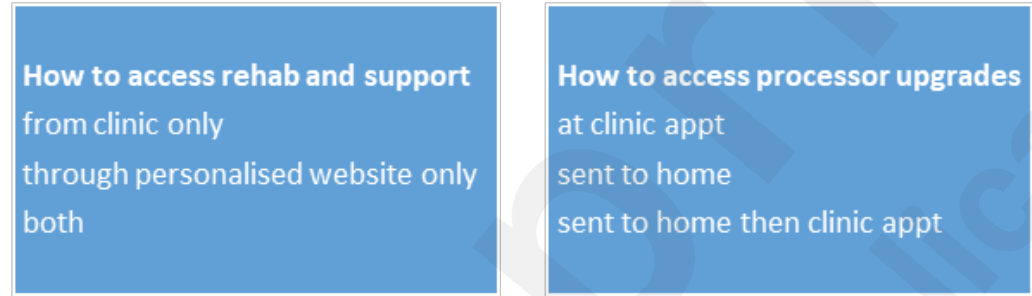

\section{Qualitative measures}

Although the qualitative fieldwork was initially planned as focus groups of patients and staff at each site, due to the Covid-19 pandemic this changed to telephone or online interviews. Up to 20 patients per site will be recruited. Interviews will be audio-recorded, transcribed and managed using NVivo 12; two Wessex AHSN qualitative evaluators will conduct all interviews.

\section{Staff outcomes}

\section{Quantitative measures}

CHOICE webapp data about staff use of the clinician dashboard will be downloaded and analysed. Staff will also be asked to complete the NHS Friends and Family Test and R-Outcomes (with additional measures on work wellbeing and innovation adoption) within the CHOICE clinician dashboard.

\section{Qualitative measures}

As for patients, focus groups were planned, but changed to telephone or online interviews due to Covid-19; up 
to 10 staff per site will be recruited for one to one interviews.

\section{Services outcomes}

\section{Quantitative measures}

Local service-level activity data will be collected at all sites, with a view to assess resource utilisation and workforce (Appendix 1). We will aim to obtain data on all clinic patients to maximise the sample size. A cohort of patients for comparison will be identified. This will comprise patients registered with the clinics but who have not yet been offered the new care model. We will look at aggregated clinical activity before introduction of the tool and after (e.g. numbers of out-patient appointments, DNAs etc. in the inclusion group). There will not be a control group of patients undergoing the same measures as the intervention group. We will also analyse centres’ previously-collected service level data to evaluate the current pathway.

\section{Process evaluation}

This part of the evaluation will assess what lessons can be learned from the implementation process and what 'key ingredients' are replicable to other clinic settings, comprising:

\section{Evaluation of the behaviours of staff involved in implementation of CHOICE}

The evaluation design is informed by Normalisation Process Theory (NPT)[40] which provides a pragmatic framework for collecting and analysing what staff do in response to changes in the model of care and the NASSS framework[41] will inform the design of the staff interviews. In addition, the NoMAD questionnaire[42] will be administered with staff early on in the roll out and later (by email at end of data collection period).

\section{Evaluation of the factors which have facilitated or hindered the adoption of CHOICE}

An analysis of findings from the qualitative data sources will be compared to factors known to be important for spread and adoption.[41] This will enable us to understand what factors facilitate or inhibit the embedding of CHOICE in the care pathway.

\section{Assessment of resource utilisation and workforce}

As this model is scaled up, it will offer important learning for how it can be delivered most efficiently and whether the anticipated changes in clinic activity and type (as a consequence of remote care options) have any implications for the clinic workforce. For example, if the reason for clinic attendance is known in advance because it is requested by the patient, the patient may not need to be seen by a senior audiologist. Data about the workforce at each site, and any changes during the project, will be collected and analysed. 
We will examine the economic impact on clinic activity of implementing the new care model. We will also apply predictive modelling to understand the impact of scaling up the model beyond the target cohort of several thousand patients. The costs associated with the delivery of follow-up activity will be sourced from each site to understand the impact of uptake of remote care.

\section{Data analysis}

All data analysis aims to answer the nine primary and secondary research questions. Statistical analysis will be performed in IBM SPSS Statistics package (version 26).

\section{Quantitative}

Descriptive statistics and graphs will be used to present data. Data will be displayed visually wherever possible in order to facilitate sharing with the varied stakeholders. The p-value for significance will be set at 0.05, including Bonferroni corrections for multiple comparisons where appropriate. All repeated measures data will be compared at baseline and follow-up using analysis of variance to examine any changes in empowerment, hearing and quality of life in the participants. Surveys will be analysed at baseline and the follow-up timepoints using inferential statistical analyses. The choices of participants in the Discrete Choice Experiment will be subjected to conditional logit model analysis using the 'survival' package of the $\mathrm{R}$ programming language.

\section{Qualitative}

The qualitative data from the patient interviews, staff interviews and the case studies will be thematically analysed separately but brought together in the triangulation phase using synthesis meetings with different investigators involved. To address the evaluation questions, qualitative findings will be synthesised with the quantitative findings. Both theoretical frameworks applied to this evaluation (NASSS and NPT) will be used to facilitate an understanding of the findings. Qualitative interview data will be coded by two qualitative evaluators (Wessex AHSN), using a coding framework based on the NASSS Framework. A small sample of transcripts will test and refine the framework with agreement between coders. The coding framework and coding of transcripts will use NVivo software. Higher order codes and themes will be presented for scrutiny and sensemaking to the wider evaluation team

\section{Missing data}

We anticipate significant missing data due to the large number of outcomes measured and the clinical population. We expect that missing data will be mostly missing not at random, as those who discontinue use of CHOICE or drop out are likely to be those who find it less helpful. This may lead to significant bias. There is likely to be selection bias, because those patients who agree to follow a remote care pathway may not 
be representative of the population. The same will apply to the clinicians: those who want to be involved in implementing CHOICE are likely to be more invested in remote care than their colleagues. Following recommendations[43], when data are ready to be analysed, inspection will suggest whether statistical methods ought to be used to handle missing data. Since this is an outcomes and process evaluation, the extent and pattern of missing data will in itself be significant, with non-response bias expected. It is also possible that reporting bias may occur; people with cochlear implants are often so grateful for their treatment that they may give answers in the direction they perceive that the researchers want.

\section{Monitoring}

\section{Steering Group}

The CHOICE Steering Group (SG) meets every 4 months and comprises the CHOICE Chief Investigator (CI), Project Manager (PM), two patients, coordinators of two other cochlear implant centres, the lead of the independent evaluation team, and senior representatives of NHS Specialist Commissioning, The Ear Foundation and the National Cochlear Implant Users Association (NCIUA). The purpose is to advise and guide the project by reflecting differing stakeholder needs to maximise the success and ensure long term sustainability of the project. The SG acts as sounding board to the project, particularly in relation to key project risks (including time, cost, quality, commercial, legal and ethical). The SG also deals with safety monitoring, adverse events, data monitoring, and deviations and breaches of protocol and major project changes.

\section{Evaluation Advisory Group}

The Evaluation Advisory Group (EAG) is a requirement of the project funder and its remit relates to the independent evaluation of CHOICE. The EAG meets every 3 months and comprises the Wessex AHSN's Director of Insight (chair), Associate Director of Insight (evaluation lead), Programme Manager, Data Analyst; the CHOICE Chief Investigator and Project Manager; a Strategic Advisor from Consilium Partners Ltd; the Director of R-Outcomes Ltd; the RUBIS.Qi Evaluation Lead (coaching organisation provided by the funder) and a patient. The CHOICE team do not take decisions on the evaluation but collaborate and provide input as required. The EAG also provides a forum to reflect on the findings of evaluation during the course of the project and enable improvements in the scaling up of CHOICE via formative learning.

\section{Industry Advisory Group}

The Industry Advisory Group (IAG) has been formed to ensure two-way dialogue with the device manufacturers of cochlear implants. This stakeholder group is purposefully separate from the SG in order that CHOICE continues its ethos of being patient centric, charity funded and agnostic of individual industry 
parties. The IAG meets every 6 months, and comprises the CI and PM and one representative from each of the four cochlear implant companies: Advanced Bionics UK Ltd, Cochlear Europe Ltd, MED-EL UK Ltd and Oticon Medical Ltd.

We have not established an independent Data Monitoring Committee as this is not a clinical trial and it is not a requirement of the funder. The funder may observe, monitor and inspect delivery of the project and reserves the right to externally evaluate any aspects of the project and its outputs. The funder may need to allow members of The Health Foundation Research Directorate to inspect anonymized records and data including recordings and transcripts of interviews with patients and others.

\section{Patient and public involvement, PPI}

The project team has a strong commitment to PPI; a member of the project team is a service user (Riggs). Local and national publicity (website, twitter, presentations to National Cochlear Implant Users' Association, newsletter articles, letters, emails, Yahoo group) have already invited help in designing the project. Several people using cochlear implants have trialled the CHOICE website and the hearing check before its release and given feedback in writing and focus groups.

A risk assessment was approved by the University of Southampton Faculty of Engineering and the Environment on 15 May 2018 (FEERA 15927).

\section{Data management}

Data will be managed according to the University of Southampton Research Data Management Policy (RDMP). Study Data Management Plan and Data Protection Impact Assessment are available on request. De-identified data will be kept at University of Southampton for at least 10 years. If patients decide to stop using CHOICE, we will keep the information we have collected so far, unless participants request it is deleted. It will not be possible to delete data if it has already been anonymised. Individual cochlear implant centres will retain their own clinical patient data according to local policies.

Evaluation data: Only de-identified data will be provided to the independent evaluator who will handle and store this in accordance with the agreements that are put in place with each site. Wessex AHSN will ensure that data are handled in line with NHS Standards including Data Collection, Code of Practice, and Information Governance. The ASHN computer network is a private, cloud-based system which is compliant to ISO27001 and approved under the NHS IG Toolkit. The cloud servers are based in the UK.

The retention schedule for data collected by Wessex AHSN is as follows: 
1. Audio recordings will be kept until publication of the evaluation report (July 2021) and then destroyed.

2. All other data, including transcriptions of the audio recordings, will be kept until 12 months after publication of the evaluation report (July 2022) and then securely transferred to University of Southampton (under the control of the Chief Investigator) to retain until 10 years after study conclusion.

\section{Ethics and dissemination}

Ethical approval was received in November 2018 from the South Central - Hampshire A Research Ethics Committee (REC reference 18/SC/0658, IRAS project ID 242575), HRA and Health and Care Research Wales (HCRW).

\section{Confidentiality}

Personal and sensitive personal data will be entered by the patient into the webapp. The patient will consent to data sharing. Data will be encrypted before transfer. At the close of the project or before, data will be deidentified (personal data removed). We cannot guarantee anonymity because adults with cochlear implants are still rare in the general population (approximately $0.01 \%$ of the UK population, or approximately 1 in 10,000 people).

Interviews (with staff and patients) will be audio-recorded with an encrypted dictaphone and transcribed. Any names used will be removed after transcription. Data relating to individuals will not be linked together i.e. individual interview and individual R-Outcomes data will not be linked. Findings will be linked through the synthesis process at an aggregate level.

Safety monitoring and reporting of adverse events will occur according to requirements of the local and national ethics committees, with full support of the sponsor.

\section{Dissemination}

Results will be presented locally, nationally and internationally. Dissemination will include but not be limited to peer-reviewed publications both online and in print, conference and meeting presentations, posters, newsletter articles, website reports, and social media. In order to inform people with cochlear implants of the results, information will be sent to the National Cochlear Implant Users' Association and other patient groups, and the USAIS patient newsletter. We have budgeted for our clinical results academic publication to be gold 
open access. The results of the evaluation will be published as a report by Wessex AHSN.

\section{results}

As of July 2021, the trial is closed and all data collection is complete. The evaluation report is expected to be published in December 2021; the research data have not been analysed yet.

\section{Discussion}

\section{Limitations}

Seven sites agreed to participate in the implementation and evaluation of CHOICE. These sites are mostly the larger adult cochlear implant centres in England. Sites were self-selected: those participating were those who expressed interest in taking part. This means that it is unlikely that these centres are representative of all UK adult cochlear implant centres; they are likely to be more willing to innovate. Since data collection will commence as soon as centres and patients join CHOICE, there will be variable periods of follow-up.

We expect significant effect modification in subgroups (for example by age, gender, cochlear implant centre, and other demographic factors). Assessing and reporting effect modification may help to identify a subset of patients who would not benefit from remote care. We attempt to control for confounding factors by collecting demographic and digital readiness data. However it is possible that there are confounders that remain unaccounted for; we will not collect data on mental health and social support, impact of Covid-19 pandemic for example. It is likely that the concurrent Covid-19 pandemic will be the largest confounding factor on the data. In addition, the coincidental launch of a manufacturer-led remote care pathway (Cochlear Remote Check) for patients with some devices is likely to confound results. The nature of recruitment for this study (cochlear implant centre choosing to be involved plus patient choosing to take part) means that there is likely to be significant bias. Patients who choose to take part in a trial of remote care may not be representative of the broader population of people with cochlear implants. Since recruitment is done via patient and clinic choice, it is not valid to have a control group of people who do not follow a remote care pathway.

We are aiming for six months of follow-up data. This may be insufficient to highlight benefits and limitations of remote care, especially in the climate of change due to Covid-19. In addition, as patients are encouraged to register for CHOICE at any point, there may be only a very short experience of using CHOICE by the end of data collection for many people.

The Patient Activation Measure may not be very sensitive to changes in empowerment in people using cochlear implants due to its medical perspective. Since this is the first time there has been a large-scale roll out of a remote care model for cochlear implants, we do not know how many people will participate. Low 
patient numbers and drop out are likely to affect the quality of the results, although reporting these will in themselves provide important information on the success of the implementation. Patients who discontinue use of CHOICE will be asked to provide the reason why they are withdrawing.

This project will present results and learning from the first scaling up of a remote care pathway for adults with cochlear implants in the UK.

\section{ACKNOWLEDGEMENTS}

The authors thank the people with cochlear implants who give so freely of their time and experience in order to improve care for others, and the cochlear implant centres who were willing to engage with new processes to help their patients.

This work was supported by The Health Foundation Scaling Up Round 3 grant number AIMS ID 536535.

The funder was not involved in the study design; collection, analysis, and interpretation of data; writing of the paper; and decision to submit for publication.

\section{CONFLICTS OF INTEREST}

Authors HC, PK, TF, KG, CR, MW and D-MW were involved in the development of the CHOICE webapp, but have no financial interest in the webapp. All authors received grant funding from The Health Foundation for this study.

HC performed private consultancy work for Cochlear (one of the cochlear implant manufacturers) from 20112017. HC has received travel grants from all four cochlear implant manufacturers, unrelated to this study. PK received grant funding from Cochlear to carry out unrelated research within the same topic area (cochlear implants). PD and AS received a separate grant from The Health Foundation for a Rapid Insight Programme during 2020-2021. Wessex AHSN is funded by NHS England, NHS Improvement and Office for Life Sciences to support innovators under contract. Some innovations have included self-management applications for other conditions. 


\section{APPENDICES}

\section{Appendix 1. Specification for quantitative activity information and source of data (services). Column 2 relates each outcome to a Research Question (RQ)}

\begin{tabular}{|c|c|c|c|c|c|}
\hline Outcome & RQ & Detail & Measures & $\begin{array}{l}\text { Source of } \\
\text { data }\end{array}$ & Timepoint \\
\hline $\begin{array}{l}\text { Spread: } \\
\text { remote care } \\
\text { tool is } \\
\text { embedded } \\
\text { in routine } \\
\text { practice }\end{array}$ & 3 & $\begin{array}{l}\text { We would } \\
\text { expect to } \\
\text { see the } \\
\text { percentage } \\
\text { of total } \\
\text { caseload } \\
\text { recommend } \\
\text { ed for } \\
\text { remote care } \\
\text { increasing } \\
\text { over the } \\
\text { duration of } \\
\text { the project. }\end{array}$ & $\begin{array}{l}\text { Total caseload of cochlear implant users } \\
\text { (one year or more post-implant), by } \\
\text { quarter } \\
\text { Number of users recommended to } \\
\text { register on CHOICE, by quarter } \\
\text { Number of patients changing back to } \\
\text { old pathway, by quarter } \\
\text { Number of users registered on } \\
\text { CHOICE, by quarter } \\
\text { Actions arising from use of the remote } \\
\text { care package, e.g. orders for } \\
\text { replacement parts } \\
\text { Number of staff registered CHOICE, by } \\
\text { quarter } \\
\text { Clinics wanting to stop offering remote } \\
\text { pathway } \\
\text { Patients wanting to continue remote } \\
\text { care after the end of the evaluation } \\
\text { \% clinics wanting to participate } \\
\text { Patients using the remote care pathway, } \\
\text { as a percentage of the total clinic } \\
\text { caseload }\end{array}$ & $\begin{array}{l}\text { Clinic / } \\
\text { Trust PAS } \\
\text { system } \\
\\
\text { CHOICE } \\
\text { registration } \\
\text { data }\end{array}$ & $\begin{array}{l}\text { At start of } \\
\text { evaluation, } \\
\text { and then } \\
\text { every } \\
\text { months, } \\
\text { beginning } 3 \\
\text { months after } \\
\text { CHOICE } \\
\text { launch }\end{array}$ \\
\hline $\begin{array}{l}\text { Balancing } \\
\text { measures }\end{array}$ & 3 & & $\begin{array}{l}\text { Contacts from patients having difficulty } \\
\text { with remote tools } \\
\text { Additional appointments to train in } \\
\text { remote care } \\
\text { Additional appointments for patients } \\
\text { concerned about results from remote } \\
\text { tools } \\
\text { Clinician caseload ratio (patients with } \\
\text { problems: straightforward patients) }\end{array}$ & $\begin{array}{l}\text { Clinic / } \\
\text { Trust PAS } \\
\text { system } \\
\\
\text { CHOICE } \\
\text { registration } \\
\text { data }\end{array}$ & Throughout \\
\hline
\end{tabular}




\begin{tabular}{|c|c|c|c|c|c|}
\hline & & & $\begin{array}{l}\text { Number of patients who register to use } \\
\text { the tool but do not log in subsequently }\end{array}$ & & \\
\hline $\begin{array}{l}\text { Equity of } \\
\text { access }\end{array}$ & 6 & $\begin{array}{l}\text { It is hoped } \\
\text { that more } \\
\text { people with } \\
\text { cochlear } \\
\text { implants } \\
\text { will access } \\
\text { follow-up } \\
\text { care if they } \\
\text { are given a } \\
\text { remote care } \\
\text { option. This } \\
\text { may } \\
\text { particularly } \\
\text { apply to } \\
\text { those who } \\
\text { live a long } \\
\text { distance } \\
\text { from the } \\
\text { clinic. Geo- } \\
\text { mapping } \\
\text { will enable } \\
\text { us to locate } \\
\text { all clinic } \\
\text { attendees - } \\
\text { to maintain } \\
\text { anonymity, } \\
\text { a patient's } \\
\text { partial } \\
\text { postcode } \\
\text { will be } \\
\text { supplied to } \\
\text { the AHSN. }\end{array}$ & 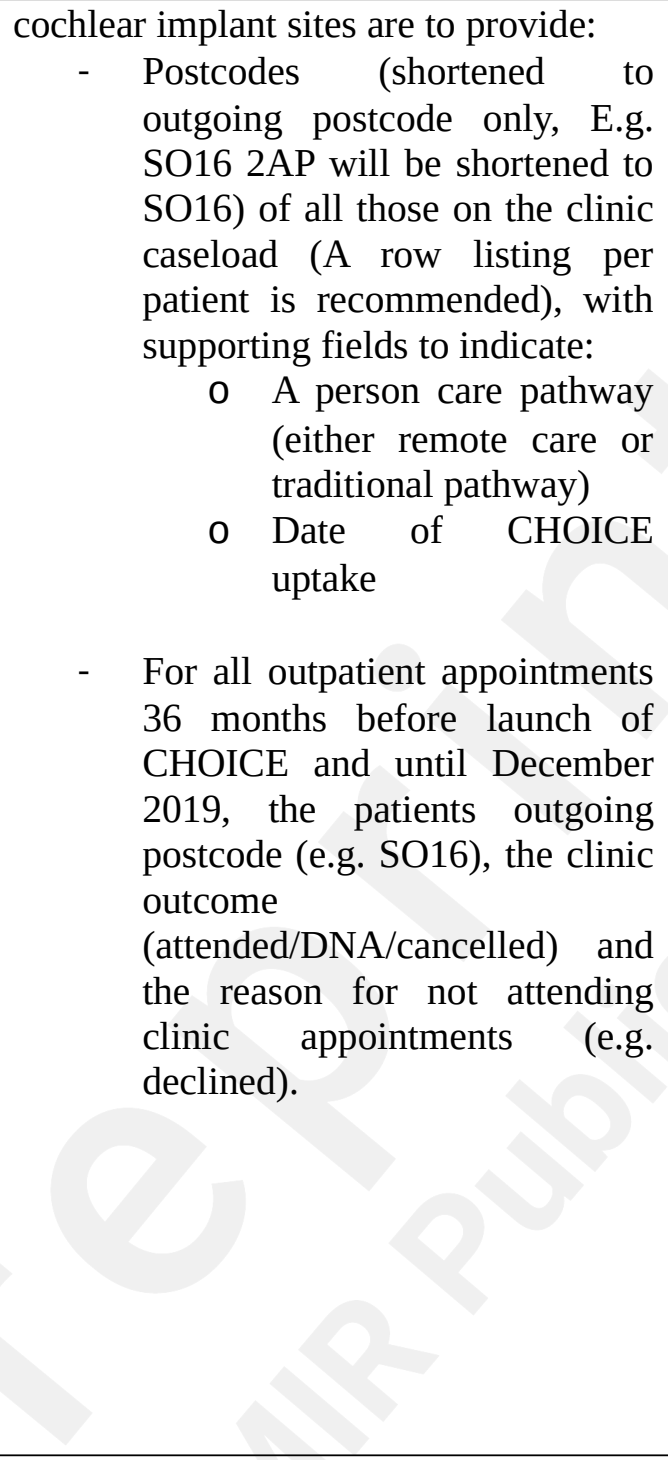 & $\begin{array}{l}\text { Clinic / } \\
\text { Trust PAS } \\
\text { system }\end{array}$ & $\begin{array}{l}\text { At start of } \\
\text { evaluation, } \\
\text { and then } \\
\text { every } \\
\text { months, } \\
\text { beginning } 3 \\
\text { months after } \\
\text { CHOICE } \\
\text { launch }\end{array}$ \\
\hline $\begin{array}{l}\text { Change in } \\
\text { use of out- } \\
\text { patient } \\
\text { appointment } \\
\text { s } \\
\text { Reduction } \\
\text { in number } \\
\text { of out- } \\
\text { patient } \\
\text { appointment } \\
\text { s (additional } \\
\text { to pre- } \\
\text { planned } \\
\text { review } \\
\text { appointment } \\
\text { s, and after } \\
\text { one year } \\
\text { post }\end{array}$ & 8 & $\begin{array}{l}\text { It is } \\
\text { expected } \\
\text { that post- } \\
\text { implementa } \\
\text { tion of the } \\
\text { remote care } \\
\text { tool, out- } \\
\text { patient } \\
\text { appointmen } \\
\text { ts will be } \\
\text { offered on a } \\
\text { request } \\
\text { basis } \\
\text { according } \\
\text { to need } \\
\text { rather than } \\
\text { on a pre- } \\
\text { planned } \\
\text { basis. We }\end{array}$ & $\begin{array}{l}\text { For each cochlear implant clinic: } \\
\text { - } \text { Total number of outpatient } \\
\text { appointments completed by the } \\
\text { clinic, by month, and by care } \\
\text { pathway (either remote care or } \\
\text { traditional pathway) for } 36 \\
\text { months before rolling out the } \\
\text { remote care system, and until } \\
\text { the end of Oct 2019, including } \\
\text { Did Not Attend rate. Outpatient } \\
\text { activity associated with care of } \\
\text { a patient in their first year of } \\
\text { having a cochlear implant } \\
\text { should be excluded. Data to } \\
\text { also include type of } \\
\text { appointment to be provided if } \\
\text { available (e.g. routine check, } \\
\text { problem (urgent/emergency } \\
\text { appointment), }\end{array}$ & $\begin{array}{l}\text { Clinic / } \\
\text { Trust PAS } \\
\text { system }\end{array}$ & $\begin{array}{l}\text { At start of } \\
\text { evaluation, } \\
\text { and then } \\
\text { every } \\
\text { months } \\
\text { beginning } 3 \\
\text { months after } \\
\text { CHOICE } \\
\text { launch }\end{array}$ \\
\hline
\end{tabular}




\begin{tabular}{|c|c|c|c|c|c|}
\hline $\begin{array}{l}\text { implant), } \\
\text { following } \\
\text { implementat } \\
\text { ion of the } \\
\text { tool }\end{array}$ & & $\begin{array}{l}\text { will need to } \\
\text { understand } \\
\text { the activity } \\
\text { of each } \\
\text { clinic } \\
\text { before } \\
\text { implementa } \\
\text { tion of the } \\
\text { remote care } \\
\text { option and } \\
\text { afterwards } \\
\text { (what } \\
\text { happens to } \\
\text { the numbers of } \\
\text { numbitient } \\
\text { out-pationt } \\
\text { appointmen } \\
\text { ts, who } \\
\text { initiates } \\
\text { them and } \\
\text { what for) } \\
\text { The out- } \\
\text { patient } \\
\text { appointmen } \\
t \text { may be } \\
\text { provided by } \\
\text { a different } \\
\text { member of } \\
\text { staff (e.g. } \\
\text { technician } \\
\text { rather than } \\
\text { clinician) if } \\
\text { the reason } \\
\text { for the } \\
\text { appointmen } \\
t \text { is known } \\
\text { in advance } \\
\text { through } \\
\text { using the } \\
\text { tool. }\end{array}$ & $\begin{array}{l}\text { appointment (e.g. upgrade) } \\
\text { For each user recommended and taking } \\
\text { up care using the remote care pathway: } \\
\text { - } \text { date registered on the on-line } \\
\text { tool } \\
\text { - } \quad \text { number of clinic appointments } \\
\text { and contacts by month for past } \\
36 \text { months (or maximum period } \\
\text { of time if user has had their } \\
\text { implant less than } 36 \\
\text { months)and end of December } \\
\text { 2019 Appointments associated } \\
\text { with the user's first year of care } \\
\text { should be excluded. } \\
\text { Field to show clinic initiated or } \\
\text { user initiated appointments (and } \\
\text { which staff type if clinic } \\
\text { initiated) } \\
\text { reason for } \\
\text { appointment out-patient } \\
\text { Role of professional who saw } \\
\text { the person (e.g. technician, } \\
\text { clinician, etc.) }\end{array}$ & & \\
\hline $\begin{array}{l}\text { Improved } \\
\text { use of } \\
\text { resources }\end{array}$ & 8 & $\begin{array}{l}\text { What is the } \\
\text { costing } \\
\text { model for } \\
\text { remote care } \\
\text { during the } \\
\text { project? } \\
\text { Aggregate } \\
\text { data on } \\
\text { number of } \\
\text { out-patient } \\
\text { appointmen } \\
\text { ts pre- and } \\
\text { post- }\end{array}$ & $\begin{array}{l}\text { Included as part of the data in } \\
\text { dataset } 1\end{array}$ & $\begin{array}{l}\text { Clinic / } \\
\text { Trust PAS } \\
\text { system }\end{array}$ & $\begin{array}{l}\text { At start of } \\
\text { evaluation, } \\
\text { and then } \\
\text { every } \\
\text { months } \\
\text { beginning } 3 \\
\text { months after } \\
\text { CHOICE } \\
\text { launch }\end{array}$ \\
\hline
\end{tabular}




\begin{tabular}{|c|c|c|c|c|c|}
\hline & & $\begin{array}{l}\text { implementa } \\
\text { tion of } \\
\text { remote care } \\
\text { pathway at } \\
\text { each site } \\
\text { should } \\
\text { show a } \\
\text { reduction in } \\
\text { out-patient } \\
\text { appointmen } \\
\text { ts } \\
\text { (excluding } \\
\text { those that } \\
\text { are required } \\
\text { as part of } \\
\text { routine } \\
\text { care) }\end{array}$ & & & \\
\hline $\begin{array}{l}\text { Possible } \\
\text { workforce } \\
\text { changes }\end{array}$ & 8 & $\begin{array}{l}\text { This detail } \\
\text { may be } \\
\text { revealed in } \\
\text { the } \\
\text { qualitative } \\
\text { work but } \\
\text { should be } \\
\text { quantified } \\
\text { where } \\
\text { possible }\end{array}$ & $\begin{array}{l}\text { Staffing complement (WTE) and job } \\
\text { roles at time of implementing remote } \\
\text { care pathway. To be updated by the } \\
\text { clinic manager throughout the project to } \\
\text { note any changes that respond to } \\
\text { implementation of the pathway. A } \\
\text { template is suggested, below. }\end{array}$ & $\begin{array}{l}\text { Clinic / } \\
\text { Trust PAS } \\
\text { system }\end{array}$ & $\begin{array}{l}\text { At start of } \\
\text { evaluation, } \\
\text { and then } \\
\text { every } \\
\text { months, } \\
\text { beginning } 3 \\
\text { months after } \\
\text { CHOICE } \\
\text { launch }\end{array}$ \\
\hline
\end{tabular}

Sample Workforce every 6 months return template

\begin{tabular}{|c|c|c|c|}
\hline $\begin{array}{l}\text { Role } \\
\text { description }\end{array}$ & $\begin{array}{l}\text { Staff grade } \\
\text { (e.g. AfC band } \\
\text { 6) }\end{array}$ & $\begin{array}{l}\text { Number of } \\
\text { WTE }\end{array}$ & $\begin{array}{l}\text { Have the responsibilities of this } \\
\text { role changed in the past } \\
\text { quarter, as a result of } \\
\text { CHOICE? }\end{array}$ \\
\hline & & & \\
\hline
\end{tabular}




\section{REFERENCES}

1. Wilson BS, Dorman MF. Cochlear implants: current designs and future possibilities. J Rehabil Res Dev. 2008;45(5):695-730. PMID: 18816422.

2. BCIG. BCIG Annual UK data collection 01/04/2019-31/03/2020. 2021 [cited 2021 April 1]; Available from: https://www.bcig.org.uk/wp-content/uploads/2021/02/25-2-21-BCIG-CI-data.pdf.

3. Cochlear Limited. Cochlear Limited annual report 2020. 2020.

4. Ear Foundation. Cochlear implants http://www.earfoundation.org.uk/files/download/1221. In: Ear Foundation information sheet, editor. 2016.

5. Peters BR, Wyss J, Manrique M. Worldwide trends in bilateral cochlear implantation. Laryngoscope. 2010 May;120 Suppl 2:S17-44. PMID: 20422715. doi: 10.1002/lary.20859.

6. European Association of Cochlear Implant Users and Cochlear Implant International Community of Action. Global Guidelines on Standards of Care for Adult Cochlear Implantation. 2021.

7. Office for National Statistics. [Archived content] National population projections, 2010-based statistical bulletin http://webarchive.nationalarchives.gov.uk/20160105160709/http://ons.gov.uk/ons/ rel/npp/national-population-projections/2010-based-projections/index.html. 2011.

8. World Health Organisation. World Report on Hearing. Geneva: 2021.

9. The Health Foundation. Person-centred care made simple. What everyone should know about person-centred care. 2016.

10. Cullington H, Kitterick P, Weal M, Margol-Gromada M. Feasibility of personalised remote long-term follow-up of people with cochlear implants: a randomised controlled trial. BMJ Open. 2018 Apr 20;8(4):e019640. PMID: 29678970. doi: 10.1136/bmjopen-2017-019640.

11. Cullington H, Kitterick P, Weal M, Margol-Gromada M. Feasibility of personalised remote long-term follow-up of people with cochlear implants: a randomised controlled trial. BMJ Open. 2018;8(4). doi: 10.1136/bmjopen-2017-019640.

12. Cullington HE. What do our service users really want? [poster]. British Cochlear Implant Group Annual Conference; Ayrshire2013.

13. Tsay IA. Using a patient-driven software tool for programming multiple cochlear implant patients simultaneously in a telemedicine setting. Thesis (PhD). US: University of Colorado at Denver; 2013.

14. $\quad$ NHS England. The NHS Long Term Plan. In: England N, editor. 2019.

15. NHS. Five year forward view. In: NHS, editor. https://www.england.nhs.uk/wp-content/uploads/2014/10/5yfv-web.pdf2014.

16. National Information Board. Personalised Health and Care 2020. Work stream 1.1: Enable me to make the right health and care choices: providing patients and the public with digital access to health and care information and transactions https://www.gov.uk/government/uploads/system/uploads/attachment_data/file/442834/

Work_Stream_1_1.pdf. 2015.

17. Panagioti M, Richardson G, Small N, Murray E, Rogers A, Kennedy A, et al. Selfmanagement support interventions to reduce health care utilisation without compromising outcomes: a systematic review and meta-analysis. BMC Health Serv Res. 2014;14:356. PMID: 25164529. doi: 10.1186/1472-6963-14-356.

18. Hibbard JH, Greene J, Shi Y, Mittler J, Scanlon D. Taking the long view: how well do patient activation scores predict outcomes four years later? Med Care Res Rev. 2015 Jun;72(3):324-37. 
PMID: 25716663. doi: 10.1177/1077558715573871.

19. Mosen DM, Schmittdiel J, Hibbard J, Sobel D, Remmers C, Bellows J. Is patient activation associated with outcomes of care for adults with chronic conditions? J Ambul Care Manage. 2007 Jan-Mar;30(1):21-9. PMID: 17170635.

20. Yardley L, Osmond A, Hare J, Wills G, Weal M, De Roure D, et al., editors. Introduction to the LifeGuide: software facilitating the development of interactive behaviour change internet interventions. The Society for the Study of Artificial Intelligence and Simulation of Behaviour; 2009; Edinburgh.

21. Smits C, Kapteyn TS, Houtgast T. Development and validation of an automatic speech-innoise screening test by telephone. Int J Audiol. 2004;43:15-28.

22. Smits C, Houtgast T. Results from the Dutch speech-in-noise screening test by telephone. Ear Hear. 2005 Feb;26(1):89-95. PMID: 15692307.

23. Smits C, Merkus P, Houtgast T. How we do it: The Dutch functional hearing-screening tests by telephone and internet. Clin Otolaryngol. 2006 Oct;31(5):436-40. PMID: 17014457. doi: 10.1111/ j.1749-4486.2006.01195.x.

24. Smits C, Theo Goverts S, Festen JM. The digits-in-noise test: assessing auditory speech recognition abilities in noise. J Acoust Soc Am. 2013 Mar;133(3):1693-706. PMID: 23464039. doi: 10.1121/1.4789933.

25. Mahafzah M. The Triple Digit Test: a self-test of speech perception in cochlear implant users. Thesis (MSc): University of Southampton; 2013.

26. Aidi T. The Triple Digit Test: A validity and feasibility study. Thesis (MSc): University of Southampton; 2015.

27. Kaandorp MW, Smits C, Merkus P, Goverts ST, Festen JM. Assessing speech recognition abilities with digits in noise in cochlear implant and hearing aid users. Int J Audiol. 2015 Jan;54(1):48-57. PMID: 25156097. doi: 10.3109/14992027.2014.945623.

28. Agyemang-Prempeh A. Telemedicine in cochlear implants: a new way of conducting long term patient follow-up. Thesis (MSc): University of Southampton; 2012.

29. BCIG. BCIG Annual Data Collection Financial Year 2017-2018 2018 [cited 201919 May 2019].

30. Elwyn G, Frosch D, Thomson R, Joseph-Williams N, Lloyd A, Kinnersley P, et al. Shared decision making: a model for clinical practice. J Gen Intern Med. 2012 Oct;27(10):1361-7. PMID: 22618581. doi: 10.1007/s11606-012-2077-6.

31. Benson T, Sizmur S, Whatling J, Arikan S, McDonald D, Ingram D. Evaluation of a new short generic measure of health status: howRu. Inform Prim Care. 2010;18(2):89-101. PMID: 21078231.

32. NHS. Friends and Family Test (FFT). 2021 [updated 1 April 2020; cited 202120 July]; Available from: https://www.nhs.uk/using-the-nhs/about-the-nhs/friends-and-family-test-fft/.

33. Hibbard JH, Mahoney ER, Stockard J, Tusler M. Development and testing of a short form of the patient activation measure. Health Serv Res. 2005 Dec;40(6 Pt 1):1918-30. PMID: 16336556. doi: 10.1111/j.1475-6773.2005.00438.x.

34. Hibbard JH, Stockard J, Mahoney ER, Tusler M. Development of the Patient Activation Measure (PAM): conceptualizing and measuring activation in patients and consumers. Health Serv Res. 2004 Aug;39(4 Pt 1):1005-26. PMID: 15230939. doi: 10.1111/j.1475-6773.2004.00269.x.

35. Kitterick PT, Fackrell K, Cullington HE. Measuring empowerment in adult cochlear implant users - The development of the CI-EMP questionnaire [poster]. British Cochlear Implant Group Meeting; London2016.

36. Herdman M, Gudex C, Lloyd A, Janssen M, Kind P, Parkin D, et al. Development and preliminary testing of the new five-level version of EQ-5D (EQ-5D-5L). Qual Life Res. 2011 Dec;20(10):1727-36. PMID: 21479777. doi: 10.1007/s11136-011-9903-X.

37. Feeny D, Furlong W, Boyle M, Torrance GW. Multi-attribute health status classification 
systems. Health Utilities Index. Pharmacoeconomics. 1995 Jun;7(6):490-502. PMID: 10155335.

38. Johnson FR, Kanninen B, Bingham M, Ozdemir S. Experimental Design for Stated Choice Studies. In: Kanninen BJ, editor. Valuing Environmental Amenities Using Stated Choice Studies: A Common Sense Approach to Theory and Practice: Springer; 2007. p. 159-202.

39. Aizaki H. Basic Functions for Supporting an Implementation of Choice Experiments in R. Journal of Statistical Software. 2012;50(c02). doi: 10.18637/jss.v050.c02.

40. May CR, Finch TL. Implementing, embedding, and integrating practices: an outline of Normalization Process Theory. Sociology. 2009;43(3):535-54.

41. Greenhalgh T, Wherton J, Papoutsi C, Lynch J, Hughes G, A'Court C, et al. Beyond Adoption: A New Framework for Theorizing and Evaluating Nonadoption, Abandonment, and Challenges to the Scale-Up, Spread, and Sustainability of Health and Care Technologies. J Med Internet Res. 2017 Nov 1;19(11):e367. PMID: 29092808. doi: 10.2196/jmir.8775.

42. Finch TL, Girling M, May CR, Mair FS, Murray E, Treweek S, et al. Improving the normalization of complex interventions: part 2 - validation of the NoMAD instrument for assessing implementation work based on normalization process theory (NPT). BMC Med Res Methodol. 2018 Nov 15;18(1):135. PMID: 30442094. doi: 10.1186/s12874-018-0591-X.

43. Jakobsen JC, Gluud C, Wetterslev J, Winkel P. When and how should multiple imputation be used for handling missing data in randomised clinical trials - a practical guide with flowcharts. BMC Med Res Methodol. 2017 2017/12/06;17(1):162. doi: 10.1186/s12874-017-0442-1.

\section{FUNDING STATEMENT}

This work was supported by The Health Foundation Scaling Up round 3 (AIMS ID 536535). 


\section{Supplementary Files}




\section{Figures}


CHOICE webapp patient dashboard.

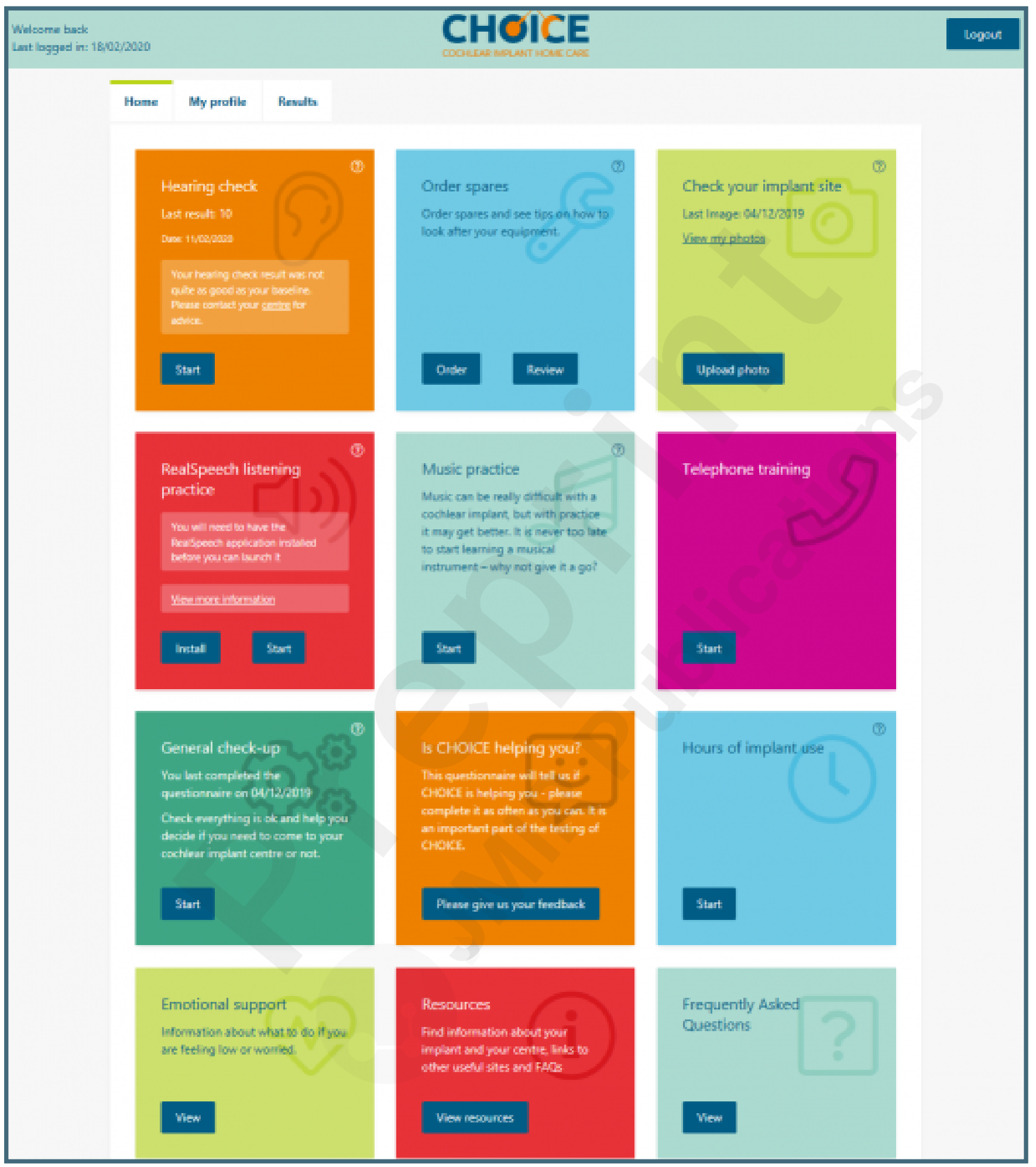


The five elements of the Discrete Choice Experiment.

Who schedules appointments?

implant clinic

patient

implant clinic and on patient

request

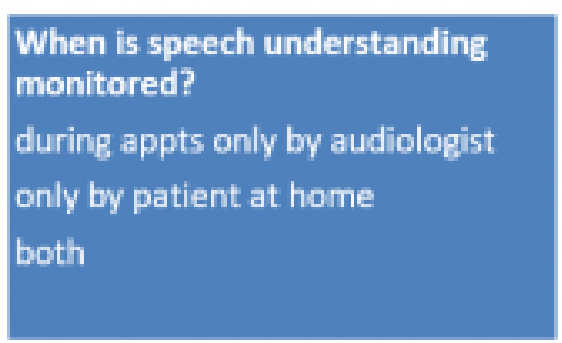

Who can fine tune the implant? during appts only by audiologist only by patient at home both
How to access rehab and support

from clinic only

through personalised website only

both
How to access processor upgrades

at clinic appt

sent to home

sent to home then clinic appt 


\section{Multimedia Appendixes}


Funder peer review.

URL: http://asset.jmir.pub/assets/88dcd01258805b1229462f5201622eef.pdf 